\title{
Spinal injuries: early surgical treatment
}

\author{
R A Dickson MA ChM FRCS \\ Professor of Orthopaedic Surgery, University of Leeds, Clinical Sciences Building, St \\ James's University Hospital, Leeds LS9 7TF, England.
}

The last decade or two has seen early surgical treatment increasingly prescribed for unstable injuries of the axial skeleton, with or without neurological involvement. Stability of course is rather difficult to define precisely, at least in practical terms. What instability really means is that the functional integrity of the spinal cord would be in jeopardy by standard non-operative medical and nursing care. This is rather confusing as those who work in spinal injury centres of excellence have treated unstable spinal injuries without surgical intervention with a great deal of care since the days of Guttmann and would readily confirm that in their careful hands the function of the spinal cord is not a worry regardless of the stability of the spine. ${ }^{1}$ In any event, surgeons have taken it upon themselves to operate upon these unstable spines and presumably they would not do so if they did not think they were benefiting the patient. There are three main reasons why surgical treatment is carried out: (1) in the hope of improving neurological outcome by reduction and stabilisation of the injury; (2) to mitigate against further neurological damage occurring as a result of non operative treatment; and (3) to prevent the painful late post-traumatic kyphosis. To what extent, however, are these aims realised by surgical intervention and how valid are the claims in favour of operative treatment?

Debate between 'operators' and 'non operators' has been going on for years since the surgical school led by Sir Astley Cooper ${ }^{2}$ took on the conservative school led by Sir Charles Bell. ${ }^{3}$ Cooper favoured early surgical intervention on the basis that as death for the paraplegic at that time was inevitable anyway, there was little to lose. It is apparently Paul of Aegina whom we have to blame for the introduction of laminectomy, ${ }^{4}$ although to be fair to the man it wasn't for the purposes of treating spinal injuries that he introduced that surgical technique. To remove the back of the spine, the only intact part of the injured spinal column locally, is surgical idiocy. Whether you subscribe to Holdsworth's two column ${ }^{5}$ or Denis's three column hypothesis ${ }^{6}$ is irrelevant; the great majority of unstable spinal injuries involve the front of the spine being squashed down while the intact, or substantially intact, posterior part of the spine is the only mechanically competent structure. One could not biomechanically devise a better operation to promote further instability, kyphosis, and further neurological loss, than laminectomy. Even more extraordinarily this procedure is not yet extinct. In this respect neurosurgeons should have bigger consciences than orthopaedic surgeons. Neither wonder that Guttmann, whose postural reduction methods achieve spontaneous spinal stability while the overall problems of the paraplegic patient are being addressed, threw up his arms in despair as more and more post-laminectomy spinal problems were referred to him. ${ }^{7}$

His attitude towards surgeons hardly improved during the phase when Meurig-Williams plates were inserted in an attempt to stabilise $^{8}$ rather than destabilise by laminectomy. He noted a very high failure rate with plates cutting out in the majority of cases. As surgeons continued to find the operative temptation irresistible, and following Harrington's development of posterior spinal instrumentation for the poliomyelitis scoliosis, ${ }^{9}$ insertion of this form of metalwork became the standard operative treatment for unstable spinal injuries. ${ }^{10}$ There is no doubt that the height of a burst vertebral body can be readily restored by distraction instrumentation but in so doing the metalwork had to bridge across 5 vertebral levels to achieve its aim. Disappointingly, when 
the metalwork was routinely removed a year or more after insertion, the spine quickly settled to much the same degree of deformity as was produced by the initial injury. Nowadays, with transpedicular metalwork, only the injured spinal segment requires instrumentation and it is eminently possible to restore vertebral height as well as sagittal contour while achieving excellent fixation and 'decompressing' the spinal canal. ${ }^{11}$ For burst fracture, with or without neurological compromise, this is the surgical procedure that is currently in vogue, but does it achieve its objectives?

First of all there is no evidence that early surgical intervention in any way favourably alters the neurological outcome, despite what the protagonists might imagine. There are two main reasons for this. Damage to the spinal cord, if it does occur, happens instantaneously at the moment of injury and occurs by way of tension not compression. The neurological damage has already occurred by the time the CT or MR scan appears to show that the spinal cord is compressed in a burst fracture by bone retropulsed from the damaged vertebral body. Indeed there is probably no compression on the spinal cord at all. After the initial tension phase with the spinal cord flexed, the vertebral body is squashed down and the spinal cord is thereby relaxed so that it is more than able to accommodate the retropulsed bone. Not surprisingly debate continues as to whether the degree of retropulsion, and thus canal compromise, positively correlates with the degree of neurological damage and whether restoration of canal dimensions in any way relates to neurological recovery. ${ }^{12,13}$ Furthermore secondary bone remodelling goes a long way to restoring the shape of the posterior column. Moreover when the spinal cord is damaged the sequence of pathological events is such that the cord either goes no further than the initial petechial haemorrhage stage (an entirely reversible situation) or goes on by a cascade of events similar to the clotting mechanism to irreversible nerve damage. Nothing surgical is going to alter this sequence of events. ${ }^{14}$

Guttmann demonstrated that postural reduction could achieve spinal stability as well as reduction of the deformity and thus claims that early surgical intervention obviates the problems of the painful progressive kyphosis only if postural reduction treatment is not carried out. This is akin to comparing open reduction and internal fixation of a joint with no treatment at all (ie no manipulation under anaesthetic). What early surgical stabilisation can do is to allow the patient to mobilise and rehabilitate as speedily as his general condition allows. ${ }^{11} \mathrm{It}$ is definitely an advantage in such patients who have been operatively stabilised to forget about the bony injury and to get on with rehabilitation but claims in favour of early surgical stabilisation should not go beyond this.

There are however some circumstances whereby early surgical stabilisation is absolutely, or relatively, indicated. ${ }^{15}$ Any circumstance whereby undue movement of the patient's spinal column is to be expected should be countered by surgical stabilisation. Thus the patient with multiple injuries whose appendicular skeleton or body cavities require surgical treatment should have preliminary spinal stabilisation. An unstable spinal injury in association with a serious head injury also demands early stabilisation lest a phase of cerebral irritation with its concomitant restlessness further damages neurologically. Finally, the fracture dislocation with considerable spinal translation requires surgical coaptation of the bony surfaces for stability purposes and this can only be achieved surgically. In these circumstances early surgical treatment is both necessary and worthwhile but there are many more problems with a paraplegic patient which can only be adequately dealt with in a specialist spinal injury treatment centre.

\section{References}

1 Frankel HL, Hancock DO, Hyslop G, et al (1969) The value of postural reduction in the initial management of closed injuries of the spine with paraplegia and tetraplegia. Paraplegia 7: 179-192. 
2 Cooper A (1824) A Treatise on Dislocation and on Fractures of the Joints. Longman, London: 499.

3 Bell C (1807) A System of Operative Surgery. Longman, London: 132.

4 Quoted by Burke DC and Murray DD (1976) The management of thoracic and thoraco-lumbar injuries of the spine with neurological involvement. J Bone Joint Surg 58B: 72-78.

5 Holdsworth FW (1963) Fractures, dislocations and fracture-dislocations of the spine. J Bone Joint Surg 45B: 6-20.

6 Denis F (1983) The three column spine and its significance in the classification of acute thoracolumbar spinal injuries. Spine 8: 817-831.

7 Guttmann L (1969) Spinal deformities in traumatic paraplegics and tetraplegics following surgical procedures. Paraplegia 7: 38-49.

8 Katznelson AM (1969) Stabilisation of the spine in traumatic paraplegia. Paraplegia 7: 33-37.

9 Harrington PR (1972) Technical details in relation to the successful use of instrumentation in scoliosis. Orthop Clin N Am 3: 49-67.

10 Dickson JH, Harrington PR and Erwin WD (1973) Harrington instrumentation in the fractured, unstable thoracic and lumbar spine. Texas Med 69: 91-98.

11 Dick W (1989) Internal Fixation of Thoracic and Lumbar Spine Fractures. Hans Huber Publishers, Toronto.

12 Dali BE, Stauffer ES (1988) Neurological injury and recovery patterns in burst fractures at the T12 or L1 motion segment. Clin Orthop 233: 171.

13 Esses SI, Botsford DJ, Kostuik JP (1990) Evaluation of surgical treatment for burst fractures. Spine 7: 667-673.

14 White RJ (1975) Pathology of spinal cord injury in experimental lesions. Clin Orthop 112: 16-26.

15 Gaines RW, Humphreys WG (1984) A plea for judgement in management of thoracolumbar fractures and fracture-dislocations. Clin Orthop 189: 36-42. 